\title{
ROMANIAN
}

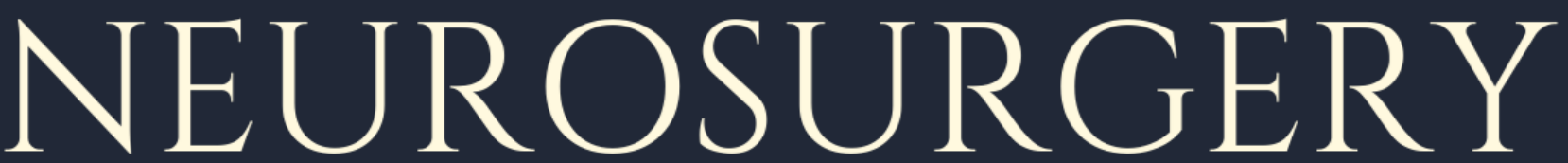

\author{
Vol. XXXIV | No. $1 \quad$ March 2020
}

The role of strict patient-positioning during nursing in the management of intracerebral migration of gravitational bullet injury

Samir H. Aldelfi, Salima B. Alsaadi, Mohammed Maan AbdulAzeez, Mukarram N. Musarhad, Mohammed D. Khudhair,

Samer S. Hoz 


\section{The role of strict patient-positioning during nursing in the management of intracerebral migration of gravitational bullet injury}

\author{
Samir H. Aldelfi ${ }^{1}$, Salima B. Alsaadi ${ }^{2}$, Mohammed \\ Maan AbdulAzeez ${ }^{3}$, Mukarram N. Musarhad ${ }^{1}$, \\ Mohammed D. Khudhair ${ }^{1}$, Samer S. Hoz ${ }^{1}$ \\ ${ }^{1}$ Neurosurgeon, Department of Neurosurgery, Neurosurgery \\ Teaching Hospital, Baghdad, IRAQ \\ 2 Radiologist, Department of Neuroradiology, Neurosurgery \\ Teaching Hospital, Baghdad, IRAQ \\ ${ }^{3}$ Medical student, College of Medicine, Baghdad University, \\ Baghdad, IRAQ
}

\begin{abstract}
The intracranial migration of bullet was described in literature since Cushing time and the First World War [1]. The literature is still away from delivering a clear guideline and constitutes more of case reports rather than comprehensive well-designed studies [2-13], this mostly due to the variability and diversity in the presentation and management of such cases. The migration of bullet can be a sequel of any type of penetrating injury to the skull [14]. Intracranial migration after gravitational (falling) bullet injury is a unique type of injury that constitutes of significant human and material losses with differences in biomechanics and structural brain changes after the insult especially regarding the velocity of impact and the degree of yaw for the intracranially settled bullet [15]. The gravitational bullets injuries are considered by the international disease classification system as celebratory firing, that is quite common and is part of the traditional happy (marriage) or funeral event in the middle east in general and in rural areas of Iraq in particular, and also reported in some areas around the world (South America, North Africa, and middle of Asia) $[15,16]$.
\end{abstract}

\section{INTRODUCTION}

In the available articles [17-28], the accepted management options for the retained intracranial bullet with possible migration, include:

- Observation, activity restriction and follow-up: for bullets with minimal risk of migration, those include small irregular bullet fragment with pure intraparanchymal location. Here, It is critical to know that the migration of bullet is rarely expected three months

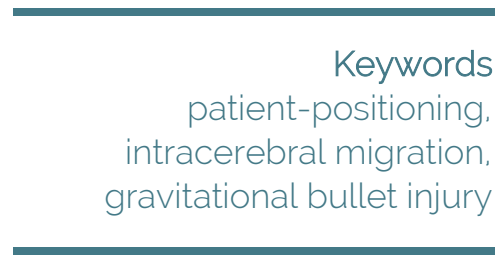

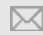

Corresponding author: Mohammed Maan AbdulAzeez

College of Medicine Baghdad University. Baghdad, Iraq

mohammed.wwt@gmail.com

Copyright and usage. This is an Open Access article distributed under the terms of the Creative Commons Attribution Non-Commercial No Derivatives License (https://creativecommons org/licenses/by-nc-nd/4.0/) which permits noncommercial re-use, distribution, and reproduction in any medium, provided the original work is unaltered and is properly cited.

The written permission of the Romanian Society of Neurosurgery must be obtained for commercial re-use or in order to create a derivative work.

ISSN online 2344-4959 (C) Romanian Society of Neurosurgery

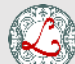

First published

London Academic Publishing wwww.lapub.co.uk 
from the insult as the gliosis (encapsulated within tough scar) will surrounds the bullet and render it extremely resistant for migration [22,28].

- Early surgery: for bullets that retained within the ventrciles that have a high risk for obstructive hydrocephalus and those just close to a hematoma cavity [22-26].

- Delayed surgery: for migrating (moving) bullet that cause new neurological symptoms, large bullets with smooth (intact) contour, resides near the ventricles, moves toward an eloquent area, migrates for a significant distance $(2.5 \mathrm{~cm})$, moves freely in the cistern with risk of neurovascular compression or injury, and those resides in accesible and safe location. Still some authors consider surgical removal of the bullet once migrated based on their personal experience [27].

\section{THEORIES ON SPONTANEOUS BULLET MIGRATION}

Although the exact mechanism is not always known or being multifactorial [21], theories suggest different explanations for the mechanism, the trajectory and the final destination of the intracranially migrated bullet.

The gravidity, the pulsating intracranial contents and softening of the surrounding tissues are the mechanism that is commonly mentioned [26].

The common expected trajectory is usually posteriorly either toward the sella turcica for bullets in the anterior cranial fossa or toward the torchula herophili for those in the posterior parietal, posterior temporal and occipital lobes. Otherwise, the trajectory will be back along the initial bullet tract (the damaged brain). In rare occasions, the bullet may take out of the above suggested directions, here, surgeons should consider abscess development as a possibility [17-20,27].

\section{PATIENT POSITIONING AFTER ADMISSION}

For cases with retained intracranial bullet after gravitational (falling) bullet head injury, where the initial decision is close clinical follow-up (nonsurgical), the patient positioning during admission is critical.

Although activity restriction is part of the general practice during this observation period, some surgeons suggest a more strict head positioning during the nursing period and consider it as pivotal part of the management of such instances $[14,28]$.
Both Rapp et al. [14] and Taarnhoj [28] describe in their reports that they use the strict patient positioning during nursing in few cases, the aim of this positioning is an attempt to change or control the direction of bullet migration in migrationpossible cases. In our practice, we routinely implement this strict-positioning technique to render a deep bullet with possible migration to an accessible and easy to remove one.

Although Rapp et al. [14] and Taarnhoj [28] document using this positioning technique for penetrating bullet injury in general, our clinical experience suggests using this technique in gravitiational (falling) bullet injury will be more fruitful taking in consideration multiple factors that are unique for the falling bullets. The gravitiational (falling) bullets are usually non-fragmented, not very small nor too large, smooth outer contour and with less adhesive surrounding brain tissue (less cavitation and necrosis as compared to other types of penetrating bullet injuries), these factors make this falling bullets are more liable for migration and also more amenable to be affected and guided by the patient positioning during the early observation period (Figure 1 shows an illustrative case scenario for the mentioned technique).

Thus, in cases of gravitational cranial bullet injury with a retained bullet that not mandate early surgery, we recommend a patient-specific activity restrictions and strict head positioning taking in consideration the possible trajectories of migration and well-designed for dragging and controlling the bullet movement into an accessible and a safe to remove destination.

Figure 1. An illustrative case for the use of strict patientpositioning during nursing in the management of intracerebral migration of gravitational bullet injury. A twelve-years-old male, a victim of gravitational bullet injury, presented to the emergency department of the neurosurgery teaching hospital. Baghdad. Iraq with disturbed consciousness (Glasgow Coma Scale 14), left side weakness (Grade 4 both upper and lower limbs), pai in the sky (contralateral upper quadrantanopia) visual field defect, with a small wound $(1 \mathrm{~cm})$ in the right frontal area (inlet). Initial lateral skull X-ray showed the frontal inlet and the posterior temporal location of the bullet $(A)$, that is confirmed by an urgent brain CT scan (C). The initial decision was to observe the patient as there were not significant wound or hematoma. The patient was put in strict supine position except for bathroom times with physiotherapy to his left side. 
Three days later, with the patient still having a severe headache, we did a follow-up skull $x$-ray then new brain CT scan that showed the migration of the bullet posteriorly ( $B$ and $D$ respectively). Here, the decision was to remove the bullet as it moved to a surgically accessible location. the surgery went uneventful and the post-operative brain CT scan showed no hematoma at the site of surgery (E). The patient discharged 4 days later, fully conscious with only the same initial visual field

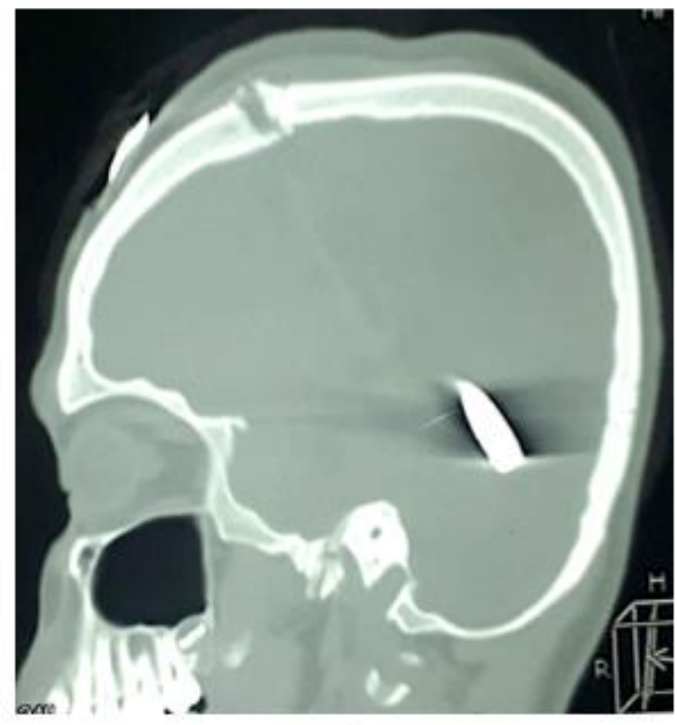

A
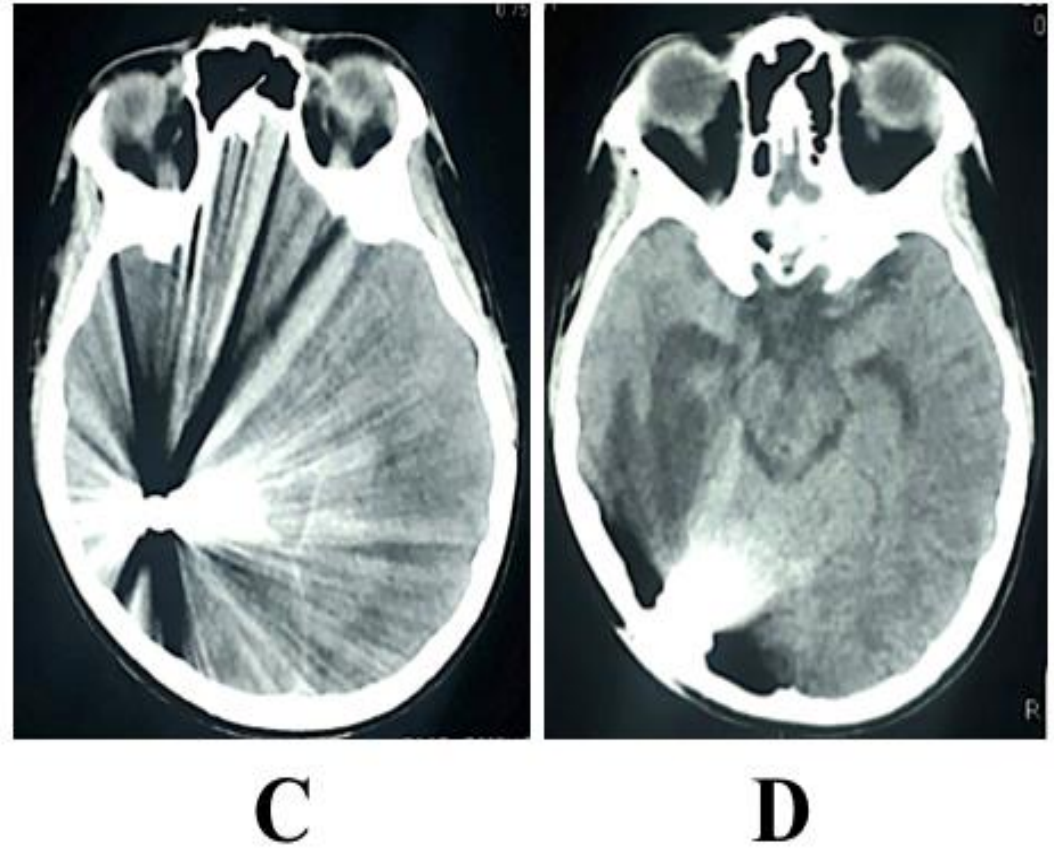

D defect. On next visits his vision improved, he returned back to school and having good marks too.

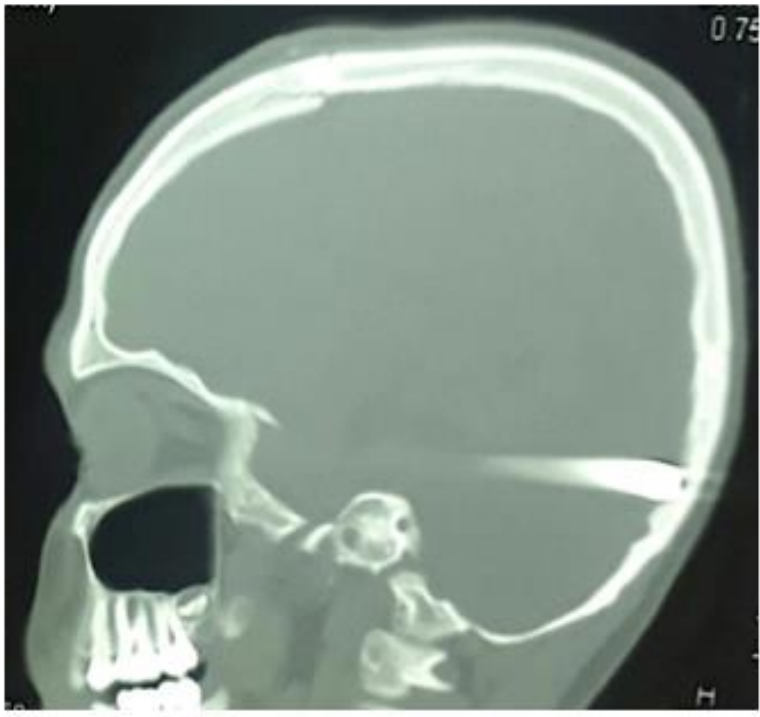

B

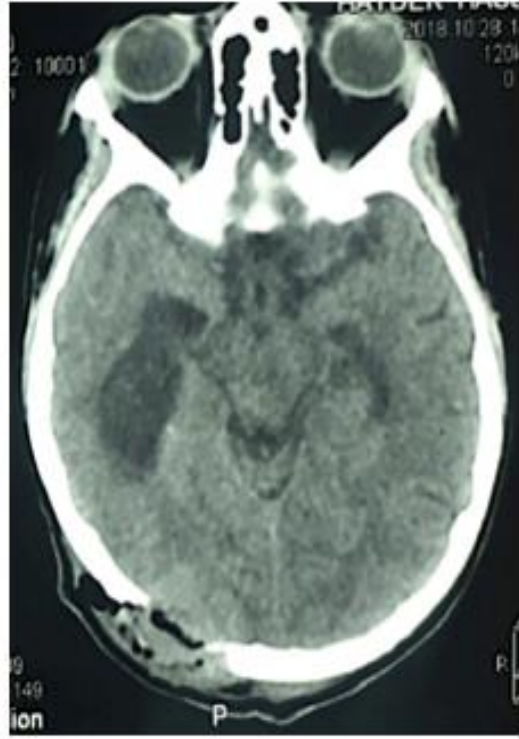

$\mathbf{E}$

\section{REFERENCES}

1. Cushing H. A study of a series of wounds involving the brain and its enveloping structures. British journal of Surgery. 1917; 5(20):558-684.

2. Duman H, Ziyal IM, Canpolat A: Spontaneous sub- falcial transcallosal migration of a missile to the contralateral hemisphere causing deterioration in neurological status- case report. Neurol Med Chir (Tokyo) 42:332333, 2002. 
3. Fujimoto Y, Cabrera HT, Pahl FH, de Andrade AF, Marino JR: Spontaneous migration of a bullet in the cerebellumcase report. Neurol Med Chir (Tokyo) 41:499-501, 2001.

4. Hughes BD, Vender JR: Delayed lead pulmonary em- boli after a gunshot wound to the head. Case report. J Neurosurg 105(3 Suppl):233-234, 2006.

5. Kamenski RS, Emch TM, Dastur KJ, Altschuler EM: Short interval spontaneous migration of an intra- cranial bullet fragment. J Trauma 65:E13-5, 2008.

6. Karabagli H: Spontaneous movement of bullets in the interhemispheric region. Pediatr Neurosurg 41: 148-150, 2005.

7. Ozkan U, Ozate,s M, Kemalog \u S, Güzel A: Spontaneous migration of a bullet into the brain. Clin Neu- rol Neurosurg 108:573-575, 2006.

8. Hussain, M., Bari, M. (2011). Intracerebral migration of stray bullet leading to sudden and fatal worsening. Journal of the College of Physicians and Surgeons Pakistan, 21(3), 182-183.

9. Kumar R, Garg P, Maurya V, Sahu RN, Mahapatra AK. Spontaneous bullet migration-uncommon sequelae of firearm injury to the brain. The Indian Journal of Neurotrauma. 2008 Dec 1;5(2):119-21.

10. AbdulAzeez MM, Dolachee AA, Huber PZ, Romario MF, Obaid HA, Arakwazi AH, Altaweel MM, Hoz SS. Intracranial ricocheted-bullet injuries: An overview and illustrative case. Journal of Acute Disease. 2018 Sep 1;7(5):186.

11. Zafonte RD, Watanabe T, Mann NR. Moving bullet syndrome: a complication of penetrating head injury. Archives of physical medicine and rehabilitation. 1998 Nov 1;79(11):1469-72.

12. Abdulrahman AL, Shudifat, Kefah Taha, et al. Migrated Intracranial Falling Bullet, Crossed Midline Twice in a Conscious Pa ent. Med Case Rep. 2016, 2:2.

13. Rapp LG, Arce CA, McKenzie R, Darmody WR, Guyot DR, Michael DB. Incidence of intracranial bullet fragment migration. Neurological research. 1999 Jul 1;21(5):475-80.

14. Abdali HA, Hoz SS, Moscote-Salazar LR. Cranial gravitational (falling) bullet injuries: Point of view. Journal of neurosciences in rural practice. 2018 Apr;9(2):278.

15. Organisation mondiale de la santé, World Health Organization, WHO Staff, WHO. The ICD-10 classification of mental and behavioural disorders: clinical descriptions and diagnostic guidelines. World Health Organization; 1992.

16. Rengachary SS, Carey M, Templer J. The sinking bullet. Neurosurgery. 1992;30:291-295.

17. Milhorat TH, Elowitz EH, Johnson RW,etal. Spontaneous movement of bullets in the brain. Neurosurgery. 1993;32:140-143.

18. Wasserman SM, Cohen JA. Spontaneous migration of an intracranial bullet fragment. Mt Sinai J Med. 1979;46:512515.

19. Leibeskind $A L$, Anderson $R D$, Schechter $M M$. Spontaneous movement of an intracranial missile. Neuroradiology. 1973;5:129-132.

20. Grant GA. Migrating intracranial bullets: a rare occurrence. World neurosurgery. 2012 Mar 1;77(3):47980.

21. Moores LE. Practical Considerations for the Management of Migrating Intracranial Bullets. World neurosurgery. 2012 Mar 1;77(3):481-3.

22. Campbell E, Howard WP, Weary WB. Gunshot wound of the brain: report of two unusual complications: bifrontal pneumocephalus and loose bullet in the lateral ventricle. Arch Surg. 1942;44:789-798.

23. Furlow LT, Bender MB, Teuber HL. Moveable foreign body within the cerebral ventricle: a case report. J Neurosurg. 1947;4:380-386.

24. Lang EK. Acute hydrocephalus secondary to occlusion of the aqueduct by a bullet. J LA Med Soc. 1969;121:167168.

25. Masoudi MS, Ghafarpasand F, Yousefi S. A Migrating Retained Intracranial Bullet Presenting with Hydrocephalus and Alterations of Consciousness: A Case Report and Literature Review. Journal of Archives in Military Medicine. 2017;5(3).

26. Raimondi AJ, Samuelson GH. Craniocerebral gunshot wounds in civilian practice. Journal of neurosurgery. 1970 Jun;32(6):647-53.

27. Taarnhoj P. Gravity Instrumental in Removing an Intracerebral Missile: Case Report. Journal of neurosurgery. 1962 Apr 1;19(4):351-2. 